\title{
ANIMAL RESEARCH PAPER Effects of pre-incubation in sheep and goat saliva on in vitro rumen digestion of tanniferous browse foliage
}

\author{
H. AMMAR ${ }^{1,2}$, R. BODAS ${ }^{1,3}$, J. S. GONZÁLEZ ${ }^{1}$, A. Z. M. SALEM ${ }^{4,5}$, F. J. GIRÁLDEZ ${ }^{1}$, S. ANDRÉS ${ }^{1}$ \\ AND S. LÓPEZ ${ }^{1} *$ \\ ${ }^{1}$ Instituto de Ganadería de Montaña, Universidad de León - Consejo Superior de Investigaciones Científicas, \\ Departamento de Producción Animal, Universidad de León, E-24071 León, Spain \\ ${ }^{2}$ Ecole Supérieure d'Agriculture de Mograne, IRESA. Mograne-Zaghouan 1121, Tunisia \\ ${ }^{3}$ Instituto Tecnológico Agrario de Castilla y León. Finca Zamadueñas. Ctra. Burgos, km 119. E-47071 Valladolid, Spain \\ ${ }^{4}$ Departamento de Nutrición Animal, Facultad de Medicina Veterinaria y Zootecnia, Universidad Autónoma del Estado de \\ México, Toluca, Estado de México, Mexico \\ ${ }^{5}$ Department of Animal Production, Faculty of Agriculture (El-Shatby), Alexandria University, Egypt
}

(Received 17 June 2011; revised 25 February 2013; accepted 11 March 2013; first published online 1 May 2013)

\section{SUMMARY}

A two-stage in vitro procedure was used for assessing the activity of parotid saliva to enhance rumen digestion of tanniniferous browse foliage. The procedure consisted of pre-incubation in saliva for $4 \mathrm{~h}$ at $39{ }^{\circ} \mathrm{C}$ followed by incubation in diluted buffered rumen fluid. Using this procedure, a study was conducted to examine the effects of pre-incubation in sheep (SS), quebracho-supplemented sheep (qSS) and goat (GS) parotid saliva or in McDougall's artificial saliva (AS, used as control) on in vitro rumen fermentation kinetics (estimated using the gas production technique) of browse foliage from six shrub species (Cytisus scoparius, Genista florida, Rosa canina, Quercus pyrenaica, Cistus laurifolius and Erica australis) collected over two seasons (spring and autumn), thus varying the in vitro digestibility (from 0.597 to 0.903) and tannin contents (from 3 to $130 \mathrm{~g}$ tannic acid equivalent/kg dry matter (DM)). Saliva was collected from four sheep and four goats fed alfalfa hay, and from four sheep fed the same alfalfa hay but supplemented with quebracho (rich in condensed tannins) for $60 \mathrm{~d}$, through a cannula inserted in the parotid duct, and rumen fluid was always from sheep fed alfalfa hay. The extent of degradation when browse foliage was pre-incubated in qSS was similar to that observed with control AS (0.449 v. 0.452, respectively), and $8 \%$ less than the value with pre-incubation in SS (0.490). In vitro fermentation kinetics (gas production parameters) of browse foliage were not significantly enhanced with pre-incubation in qSS compared with SS, whereas in vitro digestibility and extent of degradation in the rumen were significantly reduced with qSS compared with SS. After pre-incubation in sheep and goat saliva, the extent of browse foliage degradation was significantly increased by $4-8 \%$ compared with pre-incubation in the control AS. Fermentation efficiency of browse foliage was increased $(P<0 \cdot 05)$ with pre-incubation in GS compared with SS. Sheep or goat saliva may have some activity to affect in vitro rumen fermentation of the foliage samples incubated, enhancing extent of degradation of tannin-rich browse. However, a relationship between the magnitude of this effect and the tannin content of the browse foliage could not be established, suggesting that sheep and goat saliva may not be particularly important in neutralizing tannins.

\section{INTRODUCTION}

Shrubby vegetation (e.g. 'maquis' or 'garrigue' in the Mediterranean basin) is widespread throughout arid and mountain areas worldwide (Rogosic et al. 2008).

* To whom all correspondence should be addressed. Email: s.lopez@unileon.es
These rangelands represent a roughage resource for the animals of these areas, particularly during the dry summer (Ammar et al. 2004a, b; Rogosic et al. 2008). Some shrubs prevailing in arid and semi-arid rangelands have evolved defensive chemical mechanisms such as secondary compounds that limit their utilization by herbivores (Freeland 1991; Waghorn 2008). 
The consumption of substantial quantities of secondary compounds, e.g. tannins, can reduce livestock productivity significantly, and cause toxicity and health problems (Rogosic et al. 2008). Tannins are considered antinutritional compounds, with potential adverse effects such as microbial inhibition depressing ruminal fermentation and decreased feed digestibility and animal performance (Makkar 2003; Waghorn 2008). In response to plant self-protective compounds, some animals that regularly consume tannin-rich feeds develop mechanisms against these and other secondary compounds (Makkar 2003; Dearing et al. 2005). Information about the countermeasures that herbivores use to overcome the effects of specific secondary compounds is still scarce. Elucidation of these mechanisms will contribute to better understanding of the interactions between herbivores and grazing/browsing plants. One of the possible co-evolutionary mechanisms developed by some animals is the secretion of salivary compounds having a high affinity for tannins (Hagerman \& Robbins 1993; McArthur et al. 1995; Bennick 2002; Shimada 2006). Evidence of the secretion of active salivary compounds has been demonstrated in rodents (rats and mice), which can secrete tannin-binding proteins in response to ingestion of tannins. However, information regarding the occurrence and activity of salivary compounds as defences against tannins in domesticated ruminants is still controversial, and it is not yet known if these animals can resort to this feedback mechanism to reduce the negative effects associated with ingestion of tannins.

In view of the importance of saliva in rumen digestion, any changes in composition of ruminant saliva could be reflected in differences in fermentative activity in the rumen and, in particular, in degradation of tannin-rich feedstuffs. With the aim of demonstrating the role of saliva to neutralize tannins, protein composition was determined in the saliva of several herbivore species, but tannin-binding proteins were not detected in the saliva of cattle, sheep and goats (Haghighat et al. 1996; Lamy et al. 2009). In contrast with this chemical approach, Alonso-Díaz et al. (2012) examined the reactivity between saliva from sheep and goats fed tannin-rich browse and tannins extracted from different tropical plants, showing that saliva from both ruminant species can precipitate tannins to a different extent, depending upon the source of tannins. An alternative biological approach to investigate the possible interaction between tannins and ruminant saliva is to subject tannin-rich substrates to the action of saliva, examining to what extent the ruminal digestion of the test substrates is consequently affected. A two-stage in vitro procedure for assessing the potential of parotid saliva to enhance rumen digestion of tanniniferous browse foliage was devised by Ammar et al. (2011). The procedure consists of soaking browse foliage (with varying tannin contents) in saliva before incubation in rumen fluid. It can be hypothesized that if sheep or goat saliva had any activity against tannins, then the pre-incubation of browse foliage in saliva from these ruminant species would neutralize the antinutritional compounds and digestion of the substrates would be enhanced when they were incubated in rumen fluid. The comparison between sheep and goat saliva could reveal inter-species differences in the activity of saliva against tannins, which could be related to the better ability of goats, compared with sheep, to digest tannin-rich feeds (Narjisse et al. 1995; Ammar et al. 2008). With this approach, differences between each treatment (soaking in either sheep or goat saliva) and control (soaking in artificial saliva (AS) lacking any tannin-neutralizing compound) can be evaluated. To test this hypothesis, substrates with different tannin compositions and concentrations should be appraised, because if a saliva source has any activity against tannins this should become evident when tannin-rich substrates are subjected to the action of that particular saliva, whereas no effect would be observed when substrates with low tannin concentration are mixed with the same saliva source.

As information on this topic is scarce, the aim of the current work was to explore the effects of preincubation of browse foliage in sheep (consuming either a standard forage diet or a forage diet supplemented with condensed tannins) and goat saliva on in vitro rumen fermentation kinetics.

\section{MATERIALS AND METHODS}

Browse material

Foliage samples from six Spanish indigenous browse species were collected from wild scrublands in the province of León (North-west Spain) over two different seasons (for a total of 12 browse samples). The browse species were: Cytisus scoparius (L.) Link (Scotch broom), Genista florida L. (Iberian silver-leaved broom), Rosa canina L. (wild dog rose), Quercus pyrenaica Willd. (hoary oak), Cistus laurifolius L. (laurel-leaved rock-rose) and Erica australis L. (Spanish heath). C. scoparius was collected in spring and summer, whereas the other browse species were 
collected in spring and autumn. The selection of the species was based on the available information on preference and intake by sheep and goats, and on their relative abundance in the area of study, the uplands of the province of León (Northwest of Spain). A representative sample of material was collected from various specimens of each plant species. The plants were clipped with scissors, collecting a mixture of leaves and thin stems. Once in the laboratory, leaves were manually separated from the original samples, immediately freeze dried and ground in a hammer mill with a $1 \mathrm{~mm}$ sieve. Chemical composition (Ammar et al. 2004a, b), content in total extractable and condensed tannins and tannin activity (Ammar et al. 2004c), and in vitro digestibility of these browse leaves have been reported elsewhere (Ammar et al. 2011).

\section{Experimental design}

The two-stage in vitro procedure developed by Ammar et al. (2011) for assessing the activity of parotid saliva to influence rumen digestion of tanniniferous substrates was used. In vitro incubations were performed in two stages: pre-incubation in saliva followed by incubation in diluted rumen fluid. With the preincubation stage, the aim was that saliva components could interact with feed compounds so that the possible activity of saliva could be expressed. First stage incubations were conducted with parotid saliva obtained from sheep (fed alfalfa hay alone or supplemented with condensed tannins) and goats, and also with AS prepared according to McDougall (1948), used as a control treatment against which parotid saliva could be compared. In the second stage, sheep rumen liquid diluted in a buffered mineral solution was added to all the cultures. As incubation conditions during the second stage were the same in all cases, differences among experimental treatments within each substrate should be attributed to the possible effects of the pre-incubation in the different saliva sources (the only source of variation was the type of saliva).

Saliva and rumen fluid for incubations

Animal handling followed the recommendations of European Council Directive 86/609/EEC for protection of animals used for experimental and other scientific purposes, and the experimental procedures were approved by the University of León (Spain) Institutional Animal Care and Use Committee.
Four Alpine goats (mean BW $=53.2 \mathrm{~kg}$, S.D. = $2.51 \mathrm{~kg}$ ) and eight Merino sheep (mean $\mathrm{BW}=49 \cdot 2$, S.D. $=2.53 \mathrm{~kg}$ ) were housed in individual cages. All animals were adult dry non-pregnant females. Sheep and goats were fed $1 \mathrm{~kg}$ alfalfa hay once daily and had free access to fresh water and a vitamin-mineral supplement. The four goats (group GS) and four of the sheep (group SS) were fed only alfalfa hay, whereas the other four sheep (group quebracho-supplemented sheep (qSS)) were given alfalfa hay supplemented with quebracho (50 g quebracho/kg dry matter (DM)) for 60 days as described in detail by Ammar et al. (2011). Sheep of the group SS had been fitted with a permanent rumen cannula at least 3 months before the start of the trials. Rumen fluid for in vitro experiments was collected from SS sheep before hay was offered, taken immediately to the laboratory in thermos flasks, and then strained through two layers of muslin and kept at $39^{\circ} \mathrm{C}$ under $\mathrm{CO}_{2}$ atmosphere. Saliva was collected from catheters $(2.0 \mathrm{~mm}$ internal diameter, $3.0 \mathrm{~mm}$ outside diameter) inserted into the left parotid duct (via its oral papilla) and exteriorized through the cheek with a sterile hypodermic needle. Saliva secreted daily from that gland was collected into a container. In order to have enough saliva for all the trials, saliva was collected on two consecutive days, and a composite sample was obtained mixing all saliva gathered from all animals of the same experimental group (SS, qSS or GS) and in both days. This sample was stored at $-20^{\circ} \mathrm{C}$ until use.

\section{In vitro incubations}

In vitro incubations were conducted as described by Ammar et al. (2011). For the in vitro gas production technique, $400 \pm 10 \mathrm{mg}$ of each sample were weighed into $120 \mathrm{ml}$ serum bottles and pre-incubated with one of the saliva sources. In each incubation batch, eight bottles were used for each substrate (i.e. for each browse sample), two for each saliva source. Prewarmed $\left(39^{\circ} \mathrm{C}\right)$ saliva $(20 \mathrm{ml})$ was dispensed into each bottle, and then all the bottles were placed in the incubator for $4 \mathrm{~h}$ at $39^{\circ} \mathrm{C}$. With these amounts of saliva and foliage sample, the ensalivation ( $\mathrm{ml}$ saliva/g DM) was greater than mean values $(10 \mathrm{ml}$ saliva/g DM) reported for small ruminants (Kay 1966; Salem et al. 2013), and thus it was assumed that saliva was in excess to have an effect on substrate compounds.

Meanwhile, a culture medium containing bicarbonate buffer, macro- and micro-mineral, resazurin 
and reducing solutions was prepared fresh by mixing all the solutions as described by Goering \& Van Soest (1970). This culture medium was maintained under a $\mathrm{CO}_{2}$ atmosphere and at $39^{\circ} \mathrm{C}$ on a hotplate. Then, strained rumen fluid was added to the culture medium in a proportion $1: 2$ ( 1 litre of rumen fluid +2 litres of medium), and the mixture (diluted rumen fluid) was maintained at $39^{\circ} \mathrm{C}$ and under anaerobiosis. After soaking the samples in saliva for $4 \mathrm{~h}$ (first stage), $30 \mathrm{ml}$ of diluted rumen fluid $(10 \mathrm{ml}$ rumen fluid $+20 \mathrm{ml}$ culture medium) were dispensed into each bottle under anaerobiosis. All bottles were sealed and placed back into the incubator at $39^{\circ} \mathrm{C}$ for $144 \mathrm{~h}$ (incubation in diluted rumen fluid, second stage).

The volume of gas accumulated in the headspace of each bottle was measured at 3, 6, 9, 12, 16, 21, 26, $31,36,48,60,72,96,120$ and $144 \mathrm{~h}$ after inoculation, using a pressure transducer (Delta Ohm, Caselle di Selvazzano, Italy) following the procedures of Theodorou et al. (1994). After $144 \mathrm{~h}$, fermentation was stopped by swirling the bottles on ice. The contents of each bottle were filtered using glass crucibles to calculate DM disappearance (D144, g DM/g DM incubated).

Blank cultures with each saliva and diluted rumen fluid but with no substrate were incubated, and gas volumes recorded in bottles where foliage was incubated were corrected for values measured in blanks incubated with the same source of saliva (to adjust measured gas volumes for any increase in gas production due to fermentation of organic compounds contained in the corresponding parotid saliva).

Three incubations were conducted, and two serum bottles per sample and per treatment (saliva source) were used in each incubation batch (six replicates per treatment for each browse sample).

Procedures described by Ammar et al. $(1999,2011)$ were followed for in vitro digestibility. Samples of each sample were weighed into polyester bags (Ankom F57 bags, size $50 \times 50 \mathrm{~mm}$; pore size $20 \mu \mathrm{m}$ ). Bags were placed in 5-I recipients and soaked in saliva (separately for each saliva source) at $39^{\circ} \mathrm{C}$ for $4 \mathrm{~h}$ (first stage) and then incubated in diluted buffered rumen fluid for $48 \mathrm{~h}$ (second stage) as described in detail by Ammar et al. (2011). At the end of the incubations, bags were gently rinsed first under cold tap water, washed out in a neutral detergent solution at $100^{\circ} \mathrm{C}$ for $1 \mathrm{~h}$ and dried at $60^{\circ} \mathrm{C}$ for $48 \mathrm{~h}$. The dry residue was weighed and considered as the truly indigestible DM to calculate the in vitro DM digestibility (IVD, g digested/g incubated) (Goering \& Van Soest 1970).
Calculations and statistical analysis

The exponential model proposed by France et al. (2000) was fitted to gas production data to estimate fermentation kinetics:

$G=A\left[1-\mathrm{e}^{-c(t-L)}\right]$

where $G$ ( $\mathrm{ml} / \mathrm{g}$ DM incubated) denotes the cumulative gas production at time $t(\mathrm{~h}) ; A(\mathrm{ml} / \mathrm{g}$ DM incubated) is the asymptotic gas production; $c(/ h)$ is the fractional fermentation rate and $L(h)$ is the lag time.

The extent of degradation in the rumen $(d g, g$ DM/g DM) for a given fractional rate of passage $(k, / h)$ can be estimated as follows (France et al. 2000):

$d g=\frac{D 144 \times C}{c+k} \mathrm{e}^{-k L}$

where D144 is DM disappearance after $144 \mathrm{~h}$ of incubation and $k$ (fractional passage rate) was assumed to be $0.03 / \mathrm{h}$ (characteristic of sheep fed on a forage diet at maintenance level).

Average fermentation rate $(A F R, \mathrm{ml} / \mathrm{h})$ between $t=0$ and the incubation time at which $G=A / 2$ was calculated as $A F R=\frac{A \times c}{2(\ln 2+C L)}$ (France et al. 2000), and fermentation efficiency ( $\mathrm{FE}, \mathrm{mg}$ digested $\mathrm{DM} / \mathrm{ml}$ gas produced) was calculated from DM disappearance after $144 \mathrm{~h}$ of incubation and cumulative gas production measured at the same incubation time.

Effects of saliva source across all the browse samples included in the current study were tested by ANOVA using a factorial design with source of saliva (artificial, sheep, qSS and goat), browse species (six species) and sampling season (spring or summer-autumn) as fixed treatment factors, including the first-order (double) interaction effects (Steel \& Torrie 1980) in the statistical full-model. Subsequently, following the principle of parsimony, the statistical model was simplified by removing non-significant interaction terms (Crawley 2005; Pasta 2011). Level of significance ( $P$ values) of the effects of saliva source in the simplified model, and of the interactions saliva source $\times$ browse species and saliva source $\times$ season in the full model are reported. Orthogonal contrasts were performed to test the statistical significance of the difference between the control (AS) and the pooled effects (average) of SS, qSS and GS (ruminant parotid saliva), for the difference between SS and qSS, and for the difference between SS and GS (Steel \& Torrie 1980). 


\section{RESULTS}

There were large differences among foliage samples in chemical composition (in particular in tannin content) and IVD (Ammar et al. 2011) due to the different browse species included in the current study and to the different maturity stage of the plants at the two sampling seasons. Gas production values (asymptotic gas production and gas production at $24 \mathrm{~h}$ of incubation) were not affected by saliva source (Table 1). Fermentation efficiency (FE, mg DM degraded/ml gas produced) was on average higher when browse foliage were pre-incubated in GS compared with AS, SS and qSS (Table 1).

There was no significant effect of saliva source on fermentation rates (either $c$ or $A F R$ ) of browse foliage (Table 2). Lag times were shortest with SS and longest with AS $(P<0 \cdot 001)$, with qSS and GS showing intermediate values (Table 2).

Average D144 across all the browse plants was not affected by saliva source (Table 3). There were no significant differences between AS and parotid saliva (average of SS, qSS and GS) or between SS and GS in IVD and $d g$ (Table 3). However, IVD and $d g$ were decreased by pre-incubation in qSS when compared with SS (Table 3).

\section{DISCUSSION}

Saliva is involved in biological functions related to oral homeostasis, taste, sensation of astringency and digestion (Bajec \& Pickering 2008; Lamy et al. 2008). Some tannin-binding proteins have been detected in the saliva of laboratory animals, livestock and wildlife (Bennick 2002; Shimada 2006; da Costa et al. 2008). Some studies with domestic ruminants revealed a virtual absence of these compounds in the saliva of cattle, sheep and goats fed tannin-free diets (Austin et al. 1989; Haghighat et al. 1996; Lamy et al. 2009). Shimada et al. (2006) concluded that these binding agents are generally secreted in response to the ingestion of tannins. Alonso-Díaz et al. (2012) found that saliva from sheep and goats with experience of browsing native vegetation rich in tannins showed noticeable reactivity against tannic acid, concluding that this could be considered as an evidence of the presence of tannin-binding salivary proteins.

In the present study, browse foliage from different species and having different concentrations of tannins (total extractable and condensed tannins) were soaked in four saliva sources (artificial, sheep, qSS and goat
Table 1. Asymptotic gas production (A), gas production at $24 \mathrm{~h}$ of incubation (gas24) and fermentation efficiency (FE, mg DM degraded/ml gas produced) of browse foliage pre-incubated in artificial (AS), sheep (SS), quebracho-supplemented sheep (qSS) or goat (GS) saliva

\begin{tabular}{|c|c|c|c|}
\hline Saliva source & $\begin{array}{l}A(\mathrm{ml} / \mathrm{g} \mathrm{DM} \\
\text { incubated) }\end{array}$ & $\begin{array}{l}\text { gas24 } \\
\text { (ml/g DM } \\
\text { incubated) }\end{array}$ & $\mathrm{FE}$ \\
\hline AS & 200 & 133 & $3 \cdot 3$ \\
\hline SS & 204 & 143 & $3 \cdot 3$ \\
\hline qSS & 197 & 135 & $3 \cdot 4$ \\
\hline GS & 194 & 135 & $3 \cdot 6$ \\
\hline \multicolumn{4}{|l|}{$P$ values } \\
\hline Effect of saliva source & $0 \cdot 538$ & $0 \cdot 550$ & $0 \cdot 002$ \\
\hline $\begin{array}{l}\text { Contrast AS v. } \\
(\mathrm{SS}+\mathrm{qSS}+\mathrm{GS})\end{array}$ & $0 \cdot 827$ & $0 \cdot 377$ & $0 \cdot 030$ \\
\hline Contrast SS v. qSS & $0 \cdot 336$ & $0 \cdot 261$ & $0 \cdot 691$ \\
\hline Contrast SS v. GS & $0 \cdot 167$ & $0 \cdot 287$ & $0 \cdot 001$ \\
\hline \multicolumn{4}{|l|}{$\begin{array}{l}\text { Interactions in } \\
\text { the full model }\end{array}$} \\
\hline $\begin{array}{l}\text { Interaction } \\
\text { saliva } \times \text { species }\end{array}$ & $0 \cdot 023$ & $0 \cdot 040$ & $0 \cdot 224$ \\
\hline $\begin{array}{l}\text { Interaction } \\
\text { saliva } \times \text { season }\end{array}$ & $0 \cdot 144$ & $0 \cdot 498$ & $0 \cdot 367$ \\
\hline
\end{tabular}

Table 2. Fractional fermentation rate (c), lag time (Lag) and average fermentation rate (AFR) of browse foliage pre-incubated in artificial (AS), sheep (SS), quebracho-supplemented sheep (qSS) or goat (GS) saliva

\begin{tabular}{|c|c|c|c|}
\hline Saliva source & $c(/ \mathrm{h})$ & $\operatorname{Lag}(\mathrm{h})$ & $\begin{array}{l}A F R \\
(\mathrm{ml} / \mathrm{h})\end{array}$ \\
\hline AS & $0 \cdot 05$ & $1 \cdot 5$ & $6 \cdot 6$ \\
\hline SS & $0 \cdot 05$ & $0 \cdot 7$ & $7 \cdot 5$ \\
\hline qSS & $0 \cdot 05$ & $1 \cdot 0$ & $6 \cdot 8$ \\
\hline GS & $0 \cdot 05$ & $1 \cdot 2$ & $7 \cdot 0$ \\
\hline $\begin{array}{l}\text { S.E.M. } \\
\qquad P \text { values }\end{array}$ & \multicolumn{3}{|c|}{$P$ values } \\
\hline Effect of saliva source & $0 \cdot 456$ & $0 \cdot 001$ & $0 \cdot 276$ \\
\hline Contrast AS $v .(\mathrm{SS}+\mathrm{qSS}+\mathrm{GS})$ & $0 \cdot 145$ & $0 \cdot 000$ & $0 \cdot 106$ \\
\hline Contrast SS v. qSS & $0 \cdot 306$ & $0 \cdot 079$ & $0 \cdot 171$ \\
\hline Contrast SS $v$. GS & $0 \cdot 883$ & $0 \cdot 018$ & $0 \cdot 318$ \\
\hline \multicolumn{4}{|l|}{ Interactions in the full model } \\
\hline Interaction saliva $\times$ species & $0 \cdot 121$ & $0 \cdot 147$ & $0 \cdot 005$ \\
\hline Interaction saliva $\times$ season & $0 \cdot 843$ & $0 \cdot 868$ & $0 \cdot 438$ \\
\hline
\end{tabular}

saliva) and then incubated in diluted rumen fluid in vitro. Differences between parotid (sheep or goat) saliva and AS could be due to the activity of salivary compounds contained in animal saliva but not in AS 
Table 3. In vitro DM digestibility (IVD), DM disappearance after $144 \mathrm{~h}$ of incubation in vitro (D144), extent of degradation in the rumen ( $d g$, calculated from gas production kinetics, see text for details) of browse foliage pre-incubated in artificial (AS), sheep (SS), quebracho-supplemented sheep (qSS) or goat (GS) saliva

\begin{tabular}{|c|c|c|c|}
\hline Saliva source & $\begin{array}{l}\text { IVD } \\
\text { (g DM/ } \\
\text { g DM) }\end{array}$ & $\begin{array}{l}\text { D144 } \\
\text { (g DM/ } \\
\text { g DM) }\end{array}$ & $\begin{array}{l}d g \\
(\mathrm{~g} D M / \\
\text { g DM) }\end{array}$ \\
\hline AS & $0 \cdot 77$ & $0 \cdot 66$ & $0 \cdot 45$ \\
\hline SS & $0 \cdot 80$ & $0 \cdot 67$ & $0 \cdot 49$ \\
\hline qSS & $0 \cdot 75$ & $0 \cdot 66$ & $0 \cdot 45$ \\
\hline GS & $0 \cdot 78$ & $0 \cdot 68$ & $0 \cdot 47$ \\
\hline \multicolumn{4}{|l|}{$P$ values } \\
\hline Effect of saliva source & $0 \cdot 044$ & $0 \cdot 588$ & $0 \cdot 070$ \\
\hline $\begin{array}{l}\text { Contrast AS v. } \\
(\mathrm{SS}+\mathrm{qSS}+\mathrm{GS})\end{array}$ & $0 \cdot 324$ & $0 \cdot 443$ & $0 \cdot 060$ \\
\hline Contrast SS $v$. qSS & $0 \cdot 005$ & $0 \cdot 538$ & $0 \cdot 019$ \\
\hline Contrast SS v. GS & $0 \cdot 215$ & $0 \cdot 483$ & $0 \cdot 279$ \\
\hline \multicolumn{4}{|l|}{ Interactions in the full model } \\
\hline Interaction saliva $\times$ species & $0 \cdot 313$ & $0 \cdot 095$ & $0 \cdot 047$ \\
\hline Interaction saliva $\times$ season & $0 \cdot 393$ & $0 \cdot 042$ & $0 \cdot 306$ \\
\hline
\end{tabular}

(lacking any protein in its composition). On the other hand, differences between sheep and goat saliva could reflect inter-species variations in the activity of saliva against tannins, and differences between control and qSS saliva can be attributed to the response of sheep to the regular ingestion of condensed tannins (in this case those contained in quebracho) potentially changing saliva composition. This activity could be expressed during the incubation in saliva (first stage), affecting the subsequent fermentation in rumen fluid. Parotid saliva has been proved to have almost twice the tanninbinding activity compared with mixed saliva in roe deer (Fickel et al. 1998). The in vitro gas production technique was used because it is a sensitive procedure to discern changes in ruminal fermentation (Ammar et al. 2004c).

On average, and across all the browse samples included in the current study, the pre-incubation in parotid saliva tended $(P<0 \cdot 10)$ to result in greater (for SS and GS) extent of degradation than pre-incubation in AS. However, in some cases saliva source had no effect on substrates with high tannin contents $(Q$. pyrenaica, E. australis and C. laurifolius) and showed an appreciable effect on material with minor tannin concentrations (G. florida). Linear correlations (Steel \& Torrie 1980) between tannin content of browse and effects of sheep or goat saliva on in vitro ruminal fermentation kinetics (effect computed as the ratio between the values observed with either sheep or goat saliva and the value observed with AS) were determined. Pearson correlation coefficients were always low $(r<0.464, n=12)$ and never reached statistical significance. Thus, any effects of saliva cannot be explained based exclusively on a tannin-binding activity, which have not been detected in sheep and goat saliva in other reported studies (Austin et al. 1989; PerezMaldonado et al. 1995; Lamy et al. 2009). This fact could explain the inconsistency of the differences between parotid and AS observed in the present study, although it is noteworthy that parotid saliva from sheep and goats did not lower in vitro fermentation kinetics, and in some cases gave rise to enhanced ruminal fermentation compared with AS.

In the comparisons between both animal species (sheep $v$. goat saliva), no significant differences were observed, except for fermentation efficiency that was superior following pre-incubation in GS, and for the lag time that was shorter when browse was preincubated in SS than in GS. It has been accepted that goats can usually tolerate higher levels of tannins than sheep (Narjisse et al. 1995; Ammar et al. 2008), although it has been demonstrated clearly that such differences are not always evident depending on the feeding regime of the animals used in the comparison. Differences between both ruminant species are insignificant when animals are fed good quality forages, and become larger with poor quality roughages (Ammar et al. 2008). If feed offered allows for diet selection, then goats are superior in digesting fibrous forages, for they are able to select the most digestible fractions (Papachristou 1997). When tanniniferous browse material was incubated in rumen fluid from sheep and goats fed the same diet, there were no significant effects of the source of inoculum on in vitro digestibility and fermentation kinetics (Gordon et al. 2002; Ammar et al. 2008). However, as animals were adapted to ingest tannins, the microbial population in the rumen underwent changes (in the microbial communities or in their activity) enhancing the digestion of tannin rich feedstuffs (Ammar et al. 2009).

The occurrence of a salivary tannin-binding activity is not considered an inborn attribute of the animal species, as it seems rather brought about by the ingestion of tannins. The interaction between different feeding categories of herbivores (grazers or browsers) and their food resource will determine the differences 
among ruminant species in their response to cope with the digestion of tanniniferous feedstuffs (Robbins et al. 1995; Gordon 2003). Ruminant species that ingest grass have smaller salivary glands (Hofmann et al. 2008), whereas it has been observed that goats are able to increase the size of their salivary glands (and are therefore probably able to secrete more saliva) in response to the intake of tannin-rich roughages (Austin et al. 1989; Provenza et al. 1990). The development of such defensive mechanisms in goats could occur only when animals are maintained under natural conditions and consuming high levels of tannin-containing feeds. Robbins et al. (1995) concluded that anatomical differences observed among ruminant species were not always related to the animal feeding-type (grazers v. browsers). Alonso-Díaz et al. (2012) provided evidence of the differences between goat and sheep in the way that they interact with tannins from different tropical plant species, and showed that tannin-binding activity of goat saliva was greater than that of sheep saliva for some plant species (e.g. Acacia pennatula), whereas sheep saliva was superior to precipitate tannins extracted from other tropical plants (e.g. Leucaena leucocephala). In the current study, the tanning-binding activity of sheep saliva was on average greater than that observed for goat saliva.

The physiological implications of the differences between sheep and goats in the composition of their saliva has not been elucidated or related to the different feeding behaviour of these ruminant species (Lamy et al. 2008, 2009). When sheep and goats were maintained under the same dietary conditions, saliva composition was similar in both ruminant species (Lamy et al. 2009). Salivary proteins from sheep and goats browsing native vegetation rich in tannins showed a similar pattern of amino acid composition (Alonso-Díaz et al. 2012). The comparison between SS and qSS supports the results reported by Ammar et al. (2011), who concluded that saliva from sheep supplemented with quebracho tannins was not effective compared with saliva from non-supplemented sheep to offset the negative effects of tannins on digestion of browse material. Fermentation of browse foliage when pre-incubated in saliva from sheep adapted to the regular ingestion of quebracho condensed tannins (qSS) was not enhanced compared with the preincubation in saliva from sheep fed forage without tannins. According to the experimental design of the present study, differences between SS and qSS treatments could be attributed to changes in salivary composition in response to the ingestion of quebracho by
qSS animals. However, the fact that pre-incubation in SS enhanced ruminal fermentation of browse compared with qSS could also indicate a possible interaction between saliva and inoculum, as ruminal fluid was in all cases from SS sheep. In contrast, the same sheep adapted to the consumption of condensed tannins showed enhanced in vitro ruminal fermentative activity to degrade tannin-rich roughages (Ammar et al. 2009), probably due to changes in the ruminal microbial populations. However, when sheep and goats are fed the same diet and without a previous adaptation to the consumption of tannins, differences between both ruminant species in the in vitro rumen digestion of browse foliage were subtle and of little nutritional significance (Ammar et al. 2008). Further studies would be required to confirm whether adaptation mechanisms (affecting either saliva composition or ruminal microbial communities) are induced in response to a regular exposure of small ruminants to tannin-rich feedstuffs.

The differences observed in fermentation kinetics in vitro after the pre-incubation in artificial, sheep or goat saliva of foliage of some browse species with different tannin concentrations would support the hypothesis that sheep or goat saliva might have some activity to offset the detrimental effects of the tannins on ruminal fermentative activity. If the saliva from small ruminants had a specific activity to offset the effects of tannins on ruminal fermentation, then such an effect should have been more apparent when animals were adapted to the regular ingestion of tannins. However, such activity was not observed with saliva from qSS, which was less effective enhancing the ruminal degradation of tannin-rich substrates than saliva from non-adapted sheep. Additionally, the effects observed across the several foliage materials assayed were not always consistent and easily interpretable, considering the fact that tannin concentration of browse was not related to the magnitude of the effects detected. Therefore, it is not possible to conclude that the positive effect of animal saliva compared with AS is due to a neutralizing activity of tannins that is brought about by adaptation to the regular ingestion of quebracho.

Financial support received from Junta de Castilla y León (Project GR158) and from AECID (Projects $\mathrm{A} / 011878 / 07$ and $\mathrm{A} / 016261 / 08$ ) is gratefully acknowledged. RB has been granted a JAE-Doc contract from the CSIC under the programme 'Junta para la Ampliación de Estudios'. 


\section{REFERENCES}

Alonso-Díaz, M. A., Torres-Acosta, J. F. J., SandovalCastro, C. A. \& Capetillo-Leal, C. M. (2012). Amino acid profile of the protein from whole saliva of goats and sheep and its interaction with tannic acid and tannins extracted from the fodder of tropical plants. Small Ruminant Research 103, 69-74.

Ammar, H., López, S., Bochi, O., García, R. \& Ranilla, M. J. (1999). Composition and in vitro digestibility of leaves and stems of grasses and legumes harvested from permanent mountain meadows at different maturity stages. Journal of Animal and Feed Sciences 8, 599-610.

Ammar, H., López, S., González, J. S. \& Ranilla, M. J. (2004a). Chemical composition and in vitro digestibility of some Spanish browse plant species. Journal of the Science of Food and Agriculture 84, 197-204.

Ammar, H., López, S., González, J. S. \& Ranilla, M. J. (2004b). Seasonal variations in the chemical composition and in vitro digestibility of some Spanish leguminous shrub species. Animal Feed Science and Technology 115, 327-340.

Ammar, H., López, S., González, J. S. \& Ranilla, M. J. (2004c). Comparison between analytical methods and biological assays for the assessment of tannin-related antinutritive effects in some Spanish browse species. Journal of the Science of Food and Agriculture 84, 1349-1356.

Ammar, H., López, S., Andrés, S., Ranilla, M. J., Bodas, R. \& GonzÁleZ, J. S. (2008). In vitro digestibility and fermentation kinetics of some browse plants using sheep or goat ruminal fluid as the source of inoculum. Animal Feed Science and Technology 147, 90-104.

Ammar, H., López, S., Kammoun, M., Bodas, R., Giráldez, F. J. \& GonzÁlez, J. S. (2009). Feeding quebracho tannins to sheep enhances rumen fermentative activity to degrade browse shrubs. Animal Feed Science and Technology 149, 1-15.

Ammar, H., López, S., Salem, A.Z.M., Bodas, R. \& González, J. S. (2011). Effect of saliva from sheep that have ingested quebracho tannins on the in vitro rumen fermentation activity to digest tannin-containing shrubs. Animal Feed Science and Technology 163, 77-83.

Austin, P. J., Suchar, L. A., Robbins, C. T. \& Hagerman, A. E. (1989). Tannins-binding proteins in saliva of deer and their absence in saliva of sheep and cattle. Journal of Chemical Ecology 15, 1335-1347.

BAJEC, M. R. \& PiCKering, G. J. (2008). Astringency: mechanisms and perception. Critical Reviews in Food Science and Nutrition 48, 858-875.

BenNick, A. (2002). Interaction of plant polyphenols with salivary proteins. Critical Reviews in Oral Biology and Medicine 13, 184-196.

Crawley, M. J. (2005). Statistics: An Introduction Using R. Chichester, UK: John Wiley \& Sons.

da Costa, G., Lamy, E., Silva, F. C., Andersen, J., Baptista, E. S. \& Coelho, A. V. (2008). Salivary amylase induction by tannin-enriched diets as a possible countermeasure against tannins. Journal of Chemical Ecology 34, 376-387.

Dearing, M. D., Foley, W.J. \& Mclean, S. (2005). The influence of plant secondary metabolites on the nutritional ecology of herbivorous terrestrial vertebrates. Annual
Review of Ecology Evolution and Systematics 36, 169189.

Fickel, J., Goritz, F., Joest, B. A., Hildebrandt, T., Hofmann, R. R. \& Breves, G. (1998). Analysis of parotid and mixed saliva in Roe deer (Capreolus capreolus L.). Journal of Comparative Physiology B: Biochemical Systemic and Environmental Physiology 168, 257-264.

France, J., Dijkstra, J., Dhanoa, M. S., López, S. \& Bannink, A. (2000). Estimating the extent of degradation of ruminant feeds from a description of their gas production profiles observed in vitro: derivation of models and other mathematical considerations. British Journal of Nutrition 83, 143-150.

Freeland, W. J. (1991). Plant secondary metabolites: biochemical coevolution with herbivores. In Plant Defenses against Mammalian Herbivory (Eds R. T. Palo \& C. T. Robbins), pp. 61-81. Boca Raton, FL: CRC Press.

Goering, H. K. \& VAN Soest, P. J. (1970). Forage fiber analyses (apparatus, reagents, procedures, and some applications). Agriculture Handbook 379. Washington, DC: ARS-USDA.

GORDON, I. J. (2003). Browsing and grazing ruminants: are they different beasts? Forest Ecology and Management 181, 13-21.

Gordon, I. J., Perez-Barberia, F. J. \& Cuartas, P. (2002). The influence of adaptation of rumen microflora on in vitro digestion of different forages by sheep and red deer. Canadian Journal of Zoology 80, 1930-1937.

Hagerman, A. E. \& Robbins, C. T. (1993). Specificity of tannin binding salivary proteins relative to diet selection by mammals. Canadian Journal of Zoology 71, 628-633.

Haghighat, M., Moetamed, A., Vaseghi, T. \& Aminlari, $M$. (1996). Isoprenaline induces biosynthesis of proline-rich proteins in the salivary glands of rat but not in sheep. Comparative Biochemistry and Physiology Part C: Pharmacology, Toxicology and Endocrinology 115, 165168.

Hofmann, R. R., Streich, W. J., Fickel, J., Hummel, J. \& Clauss, M. (2008). Convergent evolution in feeding types: salivary gland mass differences in wild ruminant species. Journal of Morphology 269, 240-257.

KAY, R. N. B. (1966). The influence of saliva on digestion in ruminants. World Review of Nutrition and Dietetics 6, 292-325.

Lamy, E., da Costa, G., Silva, F. C., Potes, J., Coelho, A. V. \& BAPTISTA, E.S. (2008). Comparison of electrophoretic protein profiles from sheep and goat parotid saliva. Journal of Chemical Ecology 34, 388-397.

Lamy, E., da Costa, G., Santos, R., Silva, F. C., Potes, J., Pereira, A., Coelho, A. V. \& Baptista, E. S. (2009). Sheep and goat saliva proteome analysis: a useful tool for ingestive behavior research? Physiology and Behavior 98, 393-401.

MAKKAR, H.P.S. (2003). Effects and fate of tannins in ruminant animals, adaptation to tannins, and strategies to overcome detrimental effects of feeding tannin-rich feeds. Small Ruminant Research 49, 241-256.

McArthur, C., Sanson, G. D. \& Beal, A. M. (1995). Salivary proline-rich proteins in mammals-roles in oral homeostasis and counteracting dietary tannin. Journal of Chemical Ecology 21, 663-691. 
McDougall, E. I. (1948). Studies on ruminant saliva. I. The composition and output of sheep's saliva. Biochemical Journal 43, 99-109.

Narjisse, H., Elhonsali, M. A. \& Olsen, J. D. (1995). Effects of oak (Quercus ilex) tannins on digestion and nitrogen balance in sheep and goats. Small Ruminant Research 18, 201-206.

PAPAChristou, T. G. (1997). Foraging behaviour of goats and sheep on Mediterranean kermes oak shrublands. Small Ruminant Research 24, 85-93.

PASTA, D. J. (2011). Those confounded interactions: building and interpreting a model with many potential confounders and interactions. In Proceedings of the SAS Global Forum 2011, paper 347-2011. Cary, NC: SAS. Available online at http://support.sas.com/resources/papers/proceedings11/ 347-2011.pdf (verified 28 February 2013).

Perez-Maldonado, R. A., Norton, B. W. \& Kerven, G. L. (1995). Factors affecting in vitro formation of tannin protein complexes. Journal of the Science of Food and Agriculture 69, 291-298.

Provenza, F. D., Burrit, E. A., Clausen, T.P., Bryant, J.P., Reichardt, P. B. \& Diestel, R. A. (1990). Conditional flavor aversion: a mechanism for goat to avoid condensed tannins in blackbrush. American Naturalist 136, 810-828.

Robilns, C. T., Spalinger, D. E. \& Van Hoven, W. (1995). Adaptation of ruminants to browse and grass diets: are anatomical based browser-grazer interpretations valid? Oecologia 103, 208-213.
Rogosic, J., Estell, R. E., Ivankovic, S., Kezic, J. \& Razov, J. (2008). Potential mechanisms to increase shrub intake and performance of small ruminants in mediterranean shrubby ecosystems. Small Ruminant Research 74, 1-15.

Salem, A. Z. M., López, S., Ranilla, M. J. \& González, J.S. (2013). Short to medium-term effects of consumption of quebracho tannins on saliva production and composition in sheep and goats. Journal of Animal Science doi: 10.2527/jas2010-3811.

ShImAdA, T. (2006). Salivary proteins as a defense against dietary tannins. Journal of Chemical Ecology 32, 11491163.

Shimada, T., Saitoh, T., Sasaki, E., Nishitani, Y. \& Osawa, R. (2006). The role of tannin-binding salivary proteins and tannase-producing bacteria in the acclimation of the Japanese wood mouse to acorn tannins. Journal of Chemical Ecology 32, 1165-1180.

Steel, R. G. D. \& Torrie, J. H. (1980). Principles and Procedures of Statistics (2nd edn). New York: McGraw-Hill.

Theodorou, M.K., Williams, B.A., Dhanoa, M.S., Mcallan, A. B. \& France, J. (1994). A simple gas production method using a pressure transducer to determine the fermentation kinetics of ruminant feeds. Animal Feed Science and Technology 48, 185-197.

WAGHORN, G. (2008). Beneficial and detrimental effects of dietary condensed tannins for sustainable sheep and goat production - progress and challenges. Animal Feed Science and Technology 147, 116-139. 